\title{
Homeschooling: Masihkah relevan untuk pendidikan anak gifted? Sebuah kajian literatur
}

\author{
Citra Nadia Sari \\ Magister Psikologi Sains, Fakultas Psikologi, Universitas Airlangga \\ Jawa Timur, Indonesia \\ citra.nadia.sari-2019@psikologi.unair.ac.id \\ Wiwin Hendriani \\ Departemen Psikologi Pendidikan dan Perkembangan, Fakultas Psikologi, Universitas Airlangga \\ Jawa Timur, Indonesia \\ wiwin.hendriani@psikologi.unair.ac.id
}

\section{Infromasi Artikel}

\begin{tabular}{ll}
\hline Tanggal masuk & $26-03-2020$ \\
Tanggal revisi & $22-07-2020$ \\
Tanggal diterima & $23-07-2020$
\end{tabular}

Kata Kunci:

gifted;

homeschooling;

peran guru;

peran orangtua;

peran sekolah.

\section{Abstrak}

Karakteristik anak gifted yang khas dalam segi akademik dan kurangnya pelayanan akademik pada sekolah formal membuat para orangtua yang memiliki anak gifted lebih memilih untuk menyekolahkan anak di luar sekolah formal (homeschooling). Selain karena kebutuhan akademik yang berbeda, homeschooling dapat memenuhi kebutuhan akademik dan karakteristik anak gifted yang khas. Di sisi lain, homeschooling memiliki dampak negatif pada anak gifted, yaitu kurang memfasilitasi anak untuk bersosialisasi dengan teman-temannya. Kemampuan sosial anak menjadi terbatas. Artikel ini bertujuan untuk menjelaskan peran dari orang terdekat anak gifted seperti orangtua, guru, dan sekolah dalam memfasilitasi dan membantu memenuhi kebutuhan akademik anak gifted. Pencarian artikel penelitian dilakukan di 4 situs pencarian artikel penelitian internasional, yaitu ScienceDirect, SAGE, ProQuest, dan ERIC dengan tahun terbit 2011-2020. Data awal terkumpul 40 jurnal artikel dan disaring melalui kriteria inclusion dan exclusion hingga didapatkan 8 jurnal yang terdiri dari 4 jurnal kuantitatif dan 4 jurnal kualitatif. Berdasarkan hasil systematic literature review, diketahui bahwa homeschooling masih relevan untuk menjadi pilihan dengan memperhatikan beberapa peran orangtua terhadap anak gifted sebagai motivator, resource providers, advisers, monitors, counselors, dan support. Pilihan untuk menyekolahkan anak gifted di sekolah formal juga masih dapat dilakukan dengan mempertimbangkan peran guru sebagai penyampai informasi dan follow-up mengenai perkembangan akademik anak gifted di sekolah dan peran sekolah yang memfasilitasi komunikasi intens antara orangtua dan guru serta memiliki program pendidikan khusus untuk anak gifted.

\section{Abstract}

Characteristics of gifted children are unique in terms of academics and the lack of academic services in formal schools makes parents who have gifted children prefer to send their children outside of formal schooling (homeschooling). Apart from having different academic needs, homeschooling can meet the academic needs and distinctive characteristics of gifted children. On the other hand, homeschooling has a negative impact on gifted children, which is less facilitating children to socialize with their friends. Children's social abilities become limited. This article aims to explain the role of those closest to gifted children such as parents, teachers, and schools in facilitating and helping to meet the academic needs of gifted children. The research article search was conducted at 4 international research article search sites, namely ScienceDirect, SAGE, ProQuest, and ERIC with the 2011-2020 publication. Initial data collected 40 journal articles and filtered through inclusion and exclusion criteria to obtain 8 journals consisting of 4 quantitative journals and 4 qualitative journals. Based on the results of a systematic literature review, it is known that homeschooling is still relevant to be a choice by considering some of parent's role toward gifted children as motivators, resource 
providers, advisers, monitors, counselors, and support. The choice to send gifted children to formal schools can also still be made by considering teacher's role as a deliverer of information and follow-up on the academic development of gifted children in school and school's role that facilitate intense communication between parents and teachers and have special education programs for gifted students.

\section{PENDAHULUAN}

Homeschooling telah menjadi pilihan bagi keluarga dengan anak gifted selama dua dekade terakhir (Jolly \& Matthews, 2017). Pada tahun 2013, jumlah anak gifted yang menerapkan homeschooling sekitar 50.000140.000 siswa (Jolly et al., 2013). Pilihan ini bukan tanpa alasan, karena banyak orangtua yang melaporkan bahwa anak gifted mengalami stagnasi bahkan kemunduran ketika disekolahkan di sekolah formal (Jolly et al., 2013). 9 dari 12 orangtua di Amerika melaporkan bahwa ketika anak gifted disekolahkan di sekolah formal, anak gifted hanya menunjukkan perkembangan akademik yang sedikit bahkan tidak ada perkembangan akademik sama sekali (Jolly et al., 2013). Hal ini disebabkan sekolah di Amerika masih menerapkan sistem pendidikan pull-out yang tidak membantu sisi akademik anak gifted.

Kondisi ini tidak berbeda dengan penelitian yang dilakukan di India. Penelitian ini menunjukkan bahwa anak gifted memiliki kemampuan akademik yang luar biasa ketika berada di dalam keluarga, tetapi menunjukkan sedikit minat pada pendidikan bahkan prestasi yang rendah (underachievement) ketika menghadiri sekolah formal (Manasawala \& Desai, 2019).

Di Indonesia, homeschooling merupakan salah satu bentuk dari pendidikan nonformal. Disebut pendidikan nonformal karena pendidikan dilakukan di luar sekolah formal yang terdiri dari Pendidikan Dasar, Pendidikan Menengah, dan Pendidikan Tinggi (Undang-Undang Republik Indonesia Nomor 20 Tahun 2003 Pasal 14). Pendidikan nonformal yaitu jalur pendidikan di luar pendidikan formal yang dapat dilaksanakan secara terstruktur dan berjenjang (Undang-Undang Republik Indonesia Nomor 20 Tahun 2003 Pasal 1 ayat (12)). Homeschooling juga masih jarang menjadi pilihan pendidikan bagi orangtua dengan anak gifted, karena persepsi pendidikan bagi masyarakat Indonesia masih identik dengan sekolah (Aslikudin, 2015).

Anak gifted juga merupakan salah satu jenis anak berkebutuhan khusus (ABK). Anak berkebutuhan khusus yaitu anak yang mengalami keterbatasan/ keluarbiasaan baik fisik, mental-intelektual, sosial, maupun emosional yang berpengaruh secara signifikan dalam proses pertumbuhan dan perkembangannya dibandingkan dengan anak-anak lain seusianya (Peraturan Menteri Negara Pemberdayaan Perempuan dan Perlindungan Anak Republik Indonesia Nomor 10 Tahun 2011 Pasal 1 ayat (2)). Anak gifted merupakan salah satu contoh anak berkebutuhan khusus dalam segi keluarbiasaan intelektual.

Selain itu, warga negara yang memiliki potensi kecerdasan dan bakat istimewa berhak memperoleh pendidikan khusus (Undang -Undang Republik Indonesia Nomor 20 Tahun 2003 Pasal 5 ayat (4)). Pendidikan khusus yaitu pendidikan bagi peserta didik yang memiliki tingkat kesulitan dalam mengikuti proses pembelajaran karena kelainan fisik, emosional, mental, sosial, dan/ atau memiliki potensi kecerdasan dan bakat istimewa (Undang-Undang Republik Indonesia Nomor 20 Tahun 2003 Pasal 32 ayat (1)). Oleh karena itu, anak gifted yang merupakan anak berkebutuhan khusus memiliki hak atas pendidikan khusus karena memiliki potensi kecerdasan yang istimewa.

Pendidikan nonformal yang ditempuh melalui homeschooling juga memiliki landasan hukum yang sama dengan pendidikan formal mengenai hak yang diterima oleh anak gifted. Peraturan Menteri Pendidikan Nasional Republik Indonesia Nomor 34 Tahun 2006 Pasal 9 ayat (1) menyatakan bahwa peserta didik pada jalur pendidikan nonformal 
dan informal berhak mengikuti seleksi peserta didik yang memiliki potensi kecerdasan dan/ atau bakat istimewa pada tingkat satuan pendidikan pada jalur pendidikan formal. Adanya peraturan ini membuat homeschooling tidak menjadi hambatan bagi anak gifted untuk dapat memaksimalkan potensi kecerdasan yang dimiliki.

Di sisi lain, bukan berarti pilihan homeschooling ini tidak memiliki sisi negatif. Banyak orangtua dengan anak gifted yang homeschooling memiliki masalah dalam berinteraksi dengan teman sebaya. Anak gifted merasa terasing ketika mereka harus menghadiri sekolah formal. Jika semakin parah, keterasingan anak gifted ini akan menyebabkan gangguan stress bahkan kecemasan (Jolly et al., 2013). Orangtua merasakan adanya perkembangan yang tidak selaras (asynchronous development) apabila dibandingkan dengan teman sebayanya yang sudah mulai belajar bersosialisasi dengan teman lainnya.

Keterasingan ini tidak hanya dirasakan oleh anak gifted. Orangtua dari anak gifted juga mengalami keterasingan, baik orangtua yang menyekolahkan anaknya di sekolah formal maupun homeschooling (Jolly et al., 2013). Sehingga, orangtua memilih untuk menghindari membicarakan topik ini atau menggunakan kata dan kalimat yang berbeda untuk menunjukkan perbedaan kemampuan akademik anak gifted dari anak lain pada umumnya (Jolly et al., 2013).

Artikel ini bisa digunakan sebagai referensi rujukan bagi orangtua dengan anak gifted yang menghadapi situasi dilematis dalam mempertimbangkan pilihan homeschooling. Tujuan artikel ini yaitu menjelaskan peran dari orang terdekat anak gifted seperti orangtua, guru, dan sekolah dalam memfasilitasi dan membantu memenuhi kebutuhan akademik anak gifted yang unik, khas, dan berbeda dari anak lain pada umumnya. Harapan dari artikel systematic literature review ini dapat menambah wawasan dan pemahaman mengenai apa yang harus dilakukan oleh orangtua, guru, dan sekolah sebagai orang terdekat dalam memenuhi kebutuhan akademik anak gifted.

\section{METODE}

Artikel ini merupakan artikel systematic literature review. Penulis melakukan pencarian jurnal melalui situs jurnal internasional sebanyak 4 (empat) situs, yaitu Science Direct (sciencedirect.com), ProQuest (proquest. com), SAGE (journals.sagepub. com), dan ERIC (eric.ed.gov). Pencarian jurnal ilmiah dilakukan mulai tanggal 3 Maret - 9 Maret 2020. Kata kunci yang digunakan yaitu "parent's role in gifted education" DAN "teacher's role in gifted education" DAN "homeschooling for gifted student", dengan batas tahun publikasi selama 10 tahun terakhir (2011-2020). Selain itu, penulis melakukan systematic literature review menggunakan panduan PRISMA-P 2015 (Preferred Reporting Items for Systematic Review and Meta-Analysis Protocols 2015) (Moher et al., 2016).

Pemilihan jurnal ilmiah dilakukan berdasarkan beberapa prinsip kriteria inklusi dan ekslusi, yaitu: 1) artikel penelitian mengenai peran orangtua dalam pendidikan anak berbakat, 2) artikel penelitian mengenai peran guru dalam pendidikan anak berbakat, 3) homeschooling bagi anak berbakat, 4) penelitian empiris (kuantitatif dan kualitatif), 5) jurnal berbahasa inggris, 6) open access article, dan 7) full article dapat diunduh. Penulis mendapatkan 8 dari 40 jurnal artikel penelitian yang akan di-review, diantaranya 2 jurnal dari Science Direct, 4 jurnal dari SAGE, dan 2 jurnal dari ERIC. Tidak ada jurnal ilmiah yang relevan yang ditemukan di ProQuest.

\section{HASIL}

Penulis menemukan berbagai macam artikel penelitian, baik kualitatif maupun kuantitatif yang dilakukan di berbagai negara, seperti United States (Jolly et al., 2013; Jolly \& Matthews, 2012, 2017), Kanada (Pilarinos \& Solomon, 2016), Republik Ceko (Mudrak, 2011), New Zealand (Bicknell, 2014), India (Manasawala \& Desai, 2019), Turki (Çakır, 2014), dan Iran (Hosseinkhanzadeh et al., 
2013). Hasil penelitian tersebut memberikan hasil yang beragam dan saling berkaitan antara satu penelitian dengan penelitian lainnya.

Studi kuantitatif dilakukan di Kanada, New Zealand, Turki, dan Iran. Selainnya, yaitu studi kualitatif dilakukan di Republik Ceko, India, dan United States. Untuk lebih memudahkan pemahaman mengenai jurnaljurnal yang telah ditemukan, berikut rangkuman jurnal di bawah ini:

- Bicknell, 2013: Penelitian kuantitatif yang dilakukan di New Zealand terhadap 15 orangtua ( 1 orangtua untuk setiap anak gifted) bertujuan untuk mengetahui peran orangtua dalam pendidikan anak yang berbakat dalam matematika. Hasil penelitian menunjukkan bahwa orangtua merupakan figur penting sebagai motivator, resource providers, monitors, mathematics content advisers, dan mathematical learning advisers bagi pendidikan anak gifted.

- Hosseinkhanzadeh, Yeganeh, \& Taher, 2013: Penelitian kuantitatif yang dilakukan di Babol Junior High School, Iran terhadap 64 guru dan 96 orangtua bertujuan untuk mengetahui sikap orangtua dan guru mengenai penempatan pendidikan anak gifted. Hasil penelitian menunjukkan baik orangtua dan guru memiliki sikap yang negatif terhadap pendidikan integrasi dari siswa gifted.

- Çakır, 2014: Penelitian kuantitatif yang dilakukan di Institute of Gifted and Talented Students, Turki terhadap 35 siswa gifted achievers dan 24 siswa gifted underachievers yang terdiri dari kelas 3-6 bertujuan untuk mengetahui hubungan antara sikap siswa gifted underachievement terhadap lingkungan sekolah. Hasil penelitian menunjukkan semakin tinggi tingkat kelas (semakin bertambahnya usia anak), maka sikap terhadap lingkungan sekolah semakin menurun.

- Pilarinos \& Solomon, 2016: Penelitian kuantitatif yang dilakukan di Montreal Private Elementary Schools, Quebec, Kanada terhadap 48 anak gifted usia 7-11 tahun, $48 \mathrm{ibu}, 33$ ayah, dan 36 guru ber- tujuan untuk mengetahui hubungan antara gaya pengasuhan dan penyesuaian pada anak gifted. Hasil penelitian menunjukkan tidak ada hubungan antara gaya pengasuhan dan penyesuaian pada anak gifted.

- Jolly, Matthews, \& Nester, 2013: Penelitian kualitatif yang dilakukan kepada 13 orangtua (12 ibu dan 1 ayah) dengan domisili tersebar di beberapa negara bagian United States seperti Arkansas, California, Florida, Illinois, Maryland, Minnesota, Ohio, Oregon, North Carolina, dan Texas yang bersedia melakukan wawancara. Penelitian ini bertujuan untuk mengetahui perspektif orangtua mengenai homeschooling pada anak gifted. Hasil penelitian diketahui bahwa orangtua memilih homeschooling setelah melalui berbagai usaha untuk bekerjasama dengan sekolah formal dan merasa kecewa dengan kurangnya tanggungjawab dari sekolah formal untuk benar-benar memberikan pendidikan yang sesuai kepada anak gifted.

- Jolly \& Matthews, 2017: Penelitian kualitatif yang dilakukan di United States terhadap 4 ibu dari anak gifted yang juga seorang blogger. Penelitian ini bertujuan untuk mengetahui mengapa ibu yang memiliki anak gifted melakukan blogging. Hasil penelitian ditemukan 4 tema besar, yaitu unintentional homeschoolers, curriculum pivoting, reflection as progress, dan reaching forward and back.

- Manasawala \& Desai, 2019: Penelitian kualitatif single-case study terhadap 1 anak laki-laki (Aditya) berusia 7 tahun dengan IQ 145 di Maharashtra, India. Penelitian ini bertujuan untuk mengetahui pendapat orangtua dalam menghadapi kebutuhan pendidikan anak gifted. Hasil penelitian menunjukkan usia mental Aditya 2 tahun lebih tua dari usia kronologis, dan membutuhkan dukungan yang dapat memenuhi kebutuhan akademik di keluarga, sekolah, maupun di masyarakat luas.

Mudrak, 2011: Penelitian kualitatif multiplecase study terhadap 5 anak gifted (laki- 
laki, usia 8-13 tahun) dan orangtua (4 ibu, dan sepasang ayah-ibu) di Praha, Republik Ceko. Penelitian ini bertujuan untuk mengetahui pemahaman orangtua mengenai keberbakatan. Hasil penelitian menunjukkan bahwa orangtua mengonstruksikan keberbakatan sebagai bawaan sejak lahir dan sifat ini selalu stabil sehingga hal ini akan memengaruhi pencapaian yang luar biasa pada tahap selanjutnya.

Berdasarkan rangkuman jurnal penelitian, terdapat berbagai macam temuan dan hasil penelitian yang saling berkaitan satu sama lain. Sebagai contoh, pada penelitian yang dilakukan di Iran dan di United States, hasil penelitian menunjukkan bahwa baik guru maupun orangtua lebih menyetujui jika anak gifted disekolahkan di sekolah khusus yang mempunyai program pendidikan untuk anak berbakat (Hosseinkhanzadeh et al., 2013), hanya saja perbedaannya pada penelitian di United States lebih mengarah pada homeschooling (Jolly et al., 2013). Hasil penelitian ini juga didukung oleh penelitian yang dilakukan di India, yang menyatakan bahwa anak berbakat membutuhkan dukungan dari berbagai pihak baik orangtua, guru, sekolah, dan masyarakat luas untuk saling mendukung kebutuhan akademik anak gifted yang khas, unik, dan berbeda dari anak lain pada umumnya (Manasawala \& Desai, 2019).

Penelitian lain yang dilakukan di Turki mengenai sikap siswa gifted terhadap lingkungan sekolah menunjukkan bahwa siswa gifted memiliki motivasi yang tinggi di usia yang lebih muda. Seiring bertambahnya usia, motivasi siswa semakin menurun. Rendahnya motivasi ini menyebabkan siswa gifted menjadi gifted underachievers (Çakır, 2014). Untuk menjawab permasalahan ini, penelitian lain yang dilakukan di New Zealand menyatakan bahwa orangtua berperan sebagai motivator untuk anak gifted. Orangtua memiliki peran yang sangat besar dalam menguatkan dan memotivasi anak gifted agar tidak menjadi gifted underachievers. Penelitian ini juga menyebutkan bahwa orangtua juga berperan dalam menyediakan lingkungan yang men- dukung pembelajaran yang kondusif untuk anak gifted, membantu anak gifted dalam memberikan saran, mengawasi perkembangan akademik anak gifted, konselor pembelajaran yang memahami situasi anak saat ini, kesulitan dalam pembelajaran, potensi, kebutuhan dan permintaan, dan memberikan dukungan yang sesuai untuk membantu anak gifted menghadapi tantangan pembelajaran (Bicknell, 2014).

Penelitian yang lebih komprehensif dilakukan di United States pada tahun 2008 hingga 2017 (Jolly \& Matthews, 2017). Peneliti cenderung menggunakan penelitian kualitatif dan grounded research karena ingin memahami secara holistik mengenai anak gifted dan homeschooling (Jolly \& Matthews, 2017). Penelitian yang dilakukan pada tahun 2009-2010 memberikan hasil penelitian bahwa orangtua memilih menyekolahkan anak gifted di luar sekolah formal karena merasa putus asa dengan sekolah formal yang kurang bisa memenuhi harapan orangtua untuk dapat memberikan kurikulum pendidikan yang sesuai dengan kebutuhan pendidikan anak gifted setelah melalui proses kerjasama dan kolaborasi dengan sekolah-sekolah formal (Jolly et al., 2013). Penelitian lainnya yang dilakukan pada Mei 2014-Juni 2014 juga menghasilkan kesimpulan yang sama, yaitu sekolah formal kurang bisa memenuhi harapan orangtua untuk dapat memberikan kurikulum pendidikan yang sesuai dengan kebutuhan pendidikan anak gifted (Jolly \& Matthews, 2017).

Hasil penelitian di United States berbanding terbalik dengan penelitian di New Zealand. Hasil penelitian di New Zealand bahkan menunjukkan tingkat kepercayaan orangtua yang tinggi terhadap sekolah formal untuk menyelenggarakan pendidikan anak gifted (Bicknell, 2014).

Hasil penelitian yang berbeda dan saling berkaitan satu sama lain ini yang akan dibahas pada bagian selanjutnya mengenai mengapa terdapat perbedaan hasil penelitian yang dilakukan di satu negara dengan negara lain. 


\section{PEMBAHASAN}

Berdasarkan paparan hasil rangkuman jurnal penelitian, terdapat beberapa hasil penelitian yang beragam antara satu penelitian dengan penelitian lainnya. Hasil penelitian yang saling beragam ini disebabkan oleh konteks yang berbeda antara satu negara dengan negara lainnya, sehingga memberikan hasil yang berbeda pula. Pada penelitian di United States, homeschooling menjadi pilihan karena orangtua telah berusaha untuk bekerjasama dan berkolaborasi dengan sekolah formal namun memberikan hasil yang mengecewakan (Jolly et al., 2013), sedangkan orangtua di New Zealand memberikan kepercayaan kepada sekolah formal karena adanya komunikasi yang intens antara guru dan orangtua mengenai perkembangan akademik anak gifted. Orangtua selalu mendapatkan informasi dan follow-up dari guru sekolah yang cukup untuk dapat menumbuhkan rasa percaya orangtua kepada sekolah (Bicknell, 2014). Konteks sebaliknya dihadapi oleh para orangtua di United States, dimana para orangtua memilih homeschooling karena anak gifted menunjukkan perkembangan akademik yang sedikit bahkan tidak ada sama sekali sehingga homeschooling menjadi satu-satunya pilihan agar anak gifted tetap mendapatkan dukungan akademik yang sesuai dengan kemampuannya.

Konteks lainnya yang hanya ditemui pada penelitian di United States yaitu homeschooling lebih banyak ditemui pada konteks keagamaan, seperti yang disebutkan dalam penelitian sebelumnya oleh Blackner pada tahun 1998, Uecker pada tahun 2008, dan Kunzman pada tahun 2009 (Jolly et al., 2013). Konteks ini yang menyebabkan orangtua yang homeschooling tanpa dasar keagamaan cenderung mendapatkan stigma negatif dari orangtua lainnya karena dianggap memaksakan kemampuan anak. Orangtua dengan anak gifted sebisa mungkin menghindari topik pembicaraan ini, atau menggunakan kata lain untuk menjelaskan kondisi anak gifted.

Terkait dengan kemampuan sosial, hasil penelitian di Kanada menunjukkan bahwa anak gifted tidak menunjukkan adanya permasalahan pada pertemanan (Pilarinos \& Solomon, 2016), berbanding terbalik dengan hasil penelitian di United States dimana orangtua merasa bahwa anak gifted menjadi terasing dan terisolasi dengan teman sebaya ketika anak disekolahkan di sekolah formal (Jolly et al., 2013). Penelitian di Kanada juga menemukan adanya perbedaan antara orangtua dan guru, dimana orangtua menyebutkan bahwa anak gifted memiliki permasalahan pertemanan dan gangguan perilaku sedangkan guru tidak menyebutkan demikian. Tetapi, hasil penelitian menunjukkan bahwa tidak ada hubungan antara gaya pengasuhan dan penyesuaian sosial pada anak gifted. Perbedaan ini membuat orangtua dengan anak gifted memilih homeschooling, karena orangtua berpendapat bahwa orangtua yang paling mengetahui kebutuhan akademik dan sosial anak (parents know best) (Jolly et al., 2013). Disamping itu, orangtua dan guru meyakini bahwa memisahkan anak gifted dengan teman sebaya tidak akan menghambat perkembangan sosial anak gifted (Hosseinkhanzadeh et al., 2013).

Penelitian mengenai gaya pengasuhan (parenting style) orangtua dengan anak gifted juga pernah dilakukan di Amol City, Iran. Hasil penelitian menyebutkan bahwa orangtua dari anak gifted cenderung melakukan gaya pengasuhan authoritative daripada authoritarian. Gaya pengasuhan ini menumbuhkan sikap positif pada anak gifted terhadap orangtua, serta meningkatkan kesehatan mental anak gifted karena gaya pengasuhan authoritative membuat anak memiliki konsep diri lebih baik dan kecenderungan gangguan psikologis (depresi, kecemasan, stress) yang lebih rendah. Anak gifted juga lebih mudah melakukan penyesuaian psikososial dalam gaya pengasuhan authoritative daripada authoritarian (Yazdani \& Daryei, 2016).

Penelitian lain yang meneliti tentang kesehatan mental orangtua dengan exceptional children menyebutkan bahwa orangtua dengan exceptional children mengalami kondisi kesehatan mental yang lebih baik ketika 
memiliki keyakinan positif terhadap Tuhan. Sebaliknya, orangtua dengan exceptional children yang memiliki keyakinan negatif terhadap Tuhan, cenderung mengalami kondisi mental lebih buruk (Bonab \& Koohsar, 2011).

Pemisahan dalam hal akademik tetap perlu dilakukan, karena menyatukan anak gifted bersama dengan anak sebaya lainnya dapat mengurangi motivasi berprestasi, mengurangi tugas-tugas yang menantang, dan membuat anak gifted bosan dengan lingkungan sekolah (Hosseinkhanzadeh et al., 2013). Hasil penelitian ini juga linier dengan hasil penelitian lainnya yang menyatakan bahwa ketika anak gifted semakin bertambah usia, semakin rawan mengalami persepsi diri, sikap terhadap sekolah dan guru, motivasi, dan penilaian tujuan yang lebih rendah disebabkan karena tingkat perfeksionisme yang semakin meningkat (Çakır, 2014). Oleh karena itu, anak gifted cenderung memilih homeschooling seiring dengan bertambahnya usia.

Penelitian ini juga selaras dengan penelitian yang dilakukan oleh Lin pada tahun 2004 bahwa sekolah khusus untuk anak gifted lebih baik dan lebih cocok untuk pendidikan anak gifted (Hosseinkhanzadeh et al., 2013). Di Indonesia sudah ada dasar hukum yang menyatakan bahwa peserta didik pada jalur pendidikan nonformal dan informal berhak mengikuti seleksi peserta didik yang memiliki potensi kecerdasan dan/ atau bakat istimewa pada tingkat satuan pendidikan pada jalur pendidikan formal (Peraturan Menteri Pendidikan Nasional Republik Indonesia Nomor 34 Tahun 2006 Pasal 9 ayat (1)).

\section{KESIMPULAN}

Homeschooling masih relevan untuk menjadi pilihan pendidikan, apabila orangtua memahami perannya terhadap anak gifted. Orangtua memiliki peran sebagai: (1) motivator utama; (2) resource providers, yaitu menyediakan lingkungan yang mendukung pembelajaran yang kondusif untuk anak gifted; (3) advisers, yaitu membantu anak gifted dalam memberikan saran; (4) monitors, yaitu mengawasi perkembangan akademik anak gifted; (5) counselors, yaitu konselor pem- belajaran yang memahami situasi anak saat ini, kesulitan dalam pembelajaran, potensi, kebutuhan, dan permintaan; serta (6) support, yaitu memberikan dukungan yang sesuai untuk membantu anak gifted menghadapi tantangan pembelajaran.

Pilihan untuk menyekolahkan anak gifted di sekolah formal juga masih dapat dilakukan oleh orangtua. Pilihan ini dapat diambil dengan mempertimbangkan peran guru sebagai penyampai informasi dan follow-up yang tepat mengenai perkembangan akademik anak gifted di sekolah kepada orangtua.

Pemilihan sekolah juga perlu dipertimbangkan untuk memilih sekolah yang memang memiliki program pendidikan khusus untuk anak gifted, serta mewadahi dan memfasilitasi komunikasi yang intens antara orangtua dan guru.

\section{DAFTAR RUJUKAN}

Aslikudin, N. (2015). Persepsi Masyarakat tentang Pentingnya Pendidikan Formal Implikasinya dalam Sikap Kedewasaan Anak di Dusun Semoyo, Desa Sugihmas, Kecamatan Grabag, Kabupaten Magelang. Institut Agama Islam Negeri Salatiga.

Bicknell, B. (2014). Parental Roles in the Education of Mathematically Gifted and Talented Children. Gifted Child Today, 37(2), 83-93. https:// doi.org/10.1177/1076217513497576

Bonab, B. G., \& Koohsar, A. A. H. (2011). Relations between quality of image of God and mental health in parents of exceptional children. Procedia - Social and Behavioral Sciences, 29, 227-231. https://doi.org/10.1016/ j.sbspro.2011.11.229

Çakır, L. (2014). The Relationship between Underachievement of Gifted Students and their Attitudes toward School Environment. Procedia - Social and Behavioral Sciences, 152, 1034-1038. https://doi.org/10.1016/ j.sbspro.2014.09.269

Hosseinkhanzadeh, A. A., Yeganeh, T., \& Taher, M. (2013). Investigate Attitudes of Parents and Teachers About Educational Placement of Gifted Students. Procedia - Social and Behavioral Sciences, 84, 631-636. https://doi.org/10.1016/ 
j.sbspro.2013.06.616

Jolly, J. L., \& Matthews, M. S. (2012). A critique of the literature on parenting gifted learners. Journal for the Education of the Gifted, 35(3), 259-290. https:// doi.org/10.1177/0162353212451703

Jolly, J. L., \& Matthews, M. S. (2017). The Chronicles of Homeschooling Gifted Learners. Journal of School Choice, 12 (1), 123-145. https:// doi.org/10.1080/15582159.2017.135464 4

Jolly, J. L., Matthews, M. S., \& Nester, J. (2013). Homeschooling the Gifted: A Parent's Perspective. Gifted Child Quarterly, 57(2), 121-134. https:// doi.org/10.1177/0016986212469999

Peraturan Menteri Negara Pemberdayaan Perempuan dan Perlindungan Anak Republik Indonesia Nomor 10 Tahun 2011 tentang Kebijakan Penanganan Anak Berkebutuhan Khusus.

Manasawala, S., \& Desai, D. (2019). Meeting the educational needs of a gifted child: A parent's narrative. Gifted Education International, 35(3), 189-200. https:// doi.org/10.1177/0261429419863440

Moher, D., Shamseer, L., Clarke, M., Ghersi, D., Liberati, A., Petticrew, M., Shekelle, P., Stewart, L. A., Estarli, M., Barrera, E. S. A., Martínez-Rodríguez, R., Baladia, E., Agüero, S. D., Camacho, S., Buhring, K., Herrero-López, A., GilGonzález, D. M., Altman, D. G., Booth, A., ... Whitlock, E. (2016). Preferred reporting items for systematic review and meta-analysis protocols (PRISMAP) 2015 statement. Revista Espanola de Nutricion Humana y Dietetica, 20(2), 148-160. https://doi.org/10.1186/20464053-4-1

Mudrak, J. (2011). "He was born that way": Parental constructions of giftedness. High Ability Studies, 22(2), 199-217. https:// doi.org/10.1080/13598139.2011.622941

Peraturan Menteri Pendidikan Nasional Republik Indonesia Nomor 34 Tahun 2006 tentang Pembinaan Prestasi Peserta Didik yang Memiliki Potensi Kecerdasan dan/atau Bakat Istimewa.

Pilarinos, V., \& Solomon, C. R. (2016). Parenting Styles and Adjustment in Gifted Children. Gifted Child Quarterly, 61(1), 87-98. https:// doi.org/10.1177/0016986216675351
Undang-Undang Republik Indonesia Nomor 20 Tahun 2003 tentang Sistem Pendidikan Nasional.

Yazdani, S., \& Daryei, G. (2016). Parenting styles and psychosocial adjustment of gifted and normal adolescents. Pacific Science Review B: Humanities and Social Sciences, 2(3), 100-105. https:// doi.org/10.1016/j.psrb.2016.09.019 